\title{
El sexo como apuesta al azar en los graffiti de los baños universitarios
}

Sex like a chance gamble in the university restrooms graffiti

Alexander Mosquera y Dobrila Djukich de Nery ${ }^{1}$

\section{RESUMEN}

El envite y el azar no hacen referencia solo a loterías, carreras de caballos y bingos, sino a toda situación que involucre el apostar y el factor suerte: dos aspectos apreciables en el discurso lúdico amoroso-sexual, cuyo análisis sociosemiótico se aplicó a los graffiti colectados en salas sanitarias de hombres y mujeres de la Universidad del Zulia (Maracaibo, Venezuela). Los objetivos son: 1) Determinar la presencia del envite y el azar en dichos graffiti; y 2) elaborar el modelo comunicacional que subyace en ese "hacer". Este estudio se enfoca desde la perspectiva de la semiótica espacial (Greimas y Courtés, 1979; Augé, 1996; Landowski, 1997). Se obtuvieron nueve áreas lúdico-temáticas, con el predominio del juego sexual (32\%), lo que permitió construir el modelo de comunicación lúdicasexual, en el que se establece un diálogo mediato entre un jugador oferente y un jugador al azar demandante, quienes apuestan al sexo. Además, el hombre dirige su mensaje-apuesta a jugadores del mismo sexo y las mujeres han roto las barreras de un "hacer" que se consideraba exclusivo de los hombres.

Palabras clave: Envite y azar, Semiótica Espacial, discurso lúdico, graffiti en salas sanitarias.

RECIBIDO: Noviembre 2017 ACEPTADO: Diciembre 2017

\footnotetext{
${ }^{1}$ Docentes de la Universidad del Zulia (Venezuela), adscritos al Laboratorio de Investigaciones Semióticas y Antropológicas (LISA) "Dr. José Enrique Finol", miembros y expresidentes de la Asociación Venezolana de Semiótica (AVS). Maracaibo, Venezuela. Correo electrónico: aledjosmos@gmail.com amosquera@fec.luz.edu.ve / dobriladaria@gmail.com
} 


\begin{abstract}
Raise and chance is not just lotteries, horse races and bingo, but it is whichever situation that involves a gamble and the luck factor: both aspects are presented in the ludic love-sexual discourse, from graffiti collected in male and female restrooms of University of Zulia (Maracaibo, Venezuela). The objectives are: 1) Determining the presence of raise and chance in these graffiti; and 2) building the communication model that underlies this "doing". This research is focused under the spatial semiotics perspective (Greimas et Courtés, 1979; Augé, 1996; Landowski, 1997). Nine ludic-thematic areas, of which the sexual gambling (32\%) predominated, were gotten. This allowed building the ludic-sexual communication model, where a mediate dialog between an offerer gambler and a demander chance gambler, who gamble to sex, is established. Furthermore, man addresses his message-gamble to the same sex gamblers and women have broken the barriers of a "doing" that it was considered as something exclusive of men.
\end{abstract}

Key words: Raise and chance, Spatial Semiotics, ludic discourse, graffiti in restrooms.

“Contraponiéndose a los espacios públicos concebidos como lugares de neutralización de la identidad, a los espacios sin un acontecer específico, territorios del no-conflicto,

elgraffiti crea espacios identificatorios, donde se plasma otro, una figura inquietante de la alteridad urbana. Muestra el conflicto entre diversos lenguajes de las identidades ciudadanas, la diversidad, la hibridación y las contradicciones entre culturas dominantes y minoritarias". (Gándara, 2003: 119)

\title{
INTRODUCCIÓN: EL CARÁCTER LÚDICO DEL GRAFFITI
}

Este trabajo es un estudio socio-semiótico de los graffiti que aparecen en las salas sanitarias de la Universidad del Zulia (Maracaibo, Venezuela), en los cuales se manifiesta el carácter lúdico que priva en sus autores o graffiteros, traducido en la relación de envite y azar que se establece a través de las paredes de dichos espacios, en los que la "apuesta" y la "suerte" no dejan de tener pertinencia. De esta manera, se espera contribuir con la ampliación de las investigaciones que en el campo de los 


\section{Alexander Mosquera y DobrilaDjukich de Nery}

Telos Vol. 20, No. 1 (2018). 199-222

graffiti han desarrollado en Venezuela Djukich de Nery y Finol (1997, 1998a, 1998b)

y Mosquera y Djukich de Nery (2001), del Laboratorio de Investigaciones Semióticas

y Antropológicas (LISA) de la referida institución, como parte de su línea de investigación sobre las representaciones urbanas.

Esta investigación también permite conocer el graffiti en su carácter de fenómeno cultural urbano, pues se estudia un proceso comunicacional atípico que viola formas pre-establecidas y del que se origina un nuevo espacio expresivo donde coinciden la poesía y la crítica, en lo que respecta a los espacios abiertos. Esto varía al hablar de las salas sanitarias, ya que allí la intimidad brinda a los jóvenes estudiantes mayores oportunidades para crear y expresar con más libertad sus mensajes, que en este caso tienden a ser más monosémicos (predominan los del juego con contenido sexual) que en los espacios abiertos, aunque en líneas generales Gándara (2003) considera que los graffiti son una forma de expresión popular, casual y espontánea, normalmente "con contenido erótico o contestatario" (Gándara, 2003: 17). En ese sentido, el presente análisis persigue cubrir los siguientes objetivos:

1. Describir la apuesta sexual presente en los graffiti de las salas sanitarias de la universidad, como expresión de un juego de envite y azar.

2. Elaborar un modelo comunicacional que aporte elementos a la Teoría General de la Comunicación como escenario lúdico.

El aporte de esta investigación reside en su enfoque innovador, toda vez que devela la presencia del envite y el azar en el discurso lúdico amoroso-sexual, en las salas sanitarias de las universidades venezolanas. Esta afirmación se ratifica en la amplia literatura consultada, en la cual solo se ha enfocado el graffiti en su aspecto sociológico, psicológico, generacional y, en algunos casos, como arte.

\section{EL MURO COMO HUELLA LÚDICA DEL GRAFFITI}

La pared no es únicamente pared y así se aprecia en el hecho de que se ha empleado como medio o fuente de discursos simbólicos a lo largo de la historia. Más 


\section{El sexo como apuesta al azar en los graffiti de los baños universitarios}

allá de parecer una amalgama de "simples piedras", el muro ha sido convertido por la humanidad en un verdadero símbolo; unos de los más significativos representantes son el ya desaparecido Muro de Berlín (Alemania) y el Muro de los Lamentos (Israel). $\mathrm{Y}$ es que el hombre, desde que comenzó su trajinar por el planeta, ha recurrido a diferentes medios para dejar plasmada la huella de su paso por el mundo, una actividad cuyo antecedente más primitivo es el petroglifo y que hoy se manifiesta bajo la forma de los graffiti. De esta manera ha logrado concretar su dimensión como ser histórico-cultural, al ser capaz, en su hacer, de conocer y transformar la realidad circundante.

Pero esa práctica no solo evidencia que los humanos utilizan diversas vías de expresión para dar cuenta de ese transitar y de su misma capacidad pensante, sino que también esos graffiti ponen al descubierto la importancia del juego en la vida cotidiana de nuestros ancestros, tal como lo revelan los restos arqueológicos en los que aparecen personas jugando, pinturas o escritos que describen el día a día del llamado Homo ludens, desde los inicios de la civilización (Martín y otros, 1995:15). Bien lo diría Jack Botermans en El Libro de los Juegos: "Cada día, en cada momento, se juega en los cuatro rincones del mundo; los juegos constituyen una de las raras actividades humanas que consiguen trascender las monumentales barreras sociales, culturales, lingüísticas, políticas y geográficas que separan los diferentes pueblos de la Tierra" (citado por Martín y otros, 1995:15). Esto significa que lo lúdico -al igual que el graffiti- se traduce en un símbolo de entendimiento universal, en un canal de comunicación en el que la cultura lúdica de cada pueblo es reflejada.

En el mundo contemporáneo, normalmente dicho aspecto no puede desligarse del envite y el azar, términos que no solo involucran a las loterías, carreras de caballos, lances de dados, bingos, entre otros, sino que igualmente remiten a toda situación que encierra una apuesta y el factor suerte. Ambos elementos es posible apreciarlos como parte del discurso lúdico amoroso-sexual expresado por los jóvenes a través del graffiti, tanto en los muros de las calles como en los recintos universitarios de Venezuela y que remite a aquellos textos escritos al carbón o con 


\section{Alexander Mosquera y DobrilaDjukich de Nery}

Telos Vol. 20, No. 1 (2018). 199-222

pintura en las paredes de la ciudad italiana de Pompeya entre los años 70 y 79 d.C. (Gándara, 2003), entre cuyos diversos tópicos contemplaban también lo erótico. De hecho, esos graffiti pompeyanos

Estaban compuestos por mensajes verbales e icónicos que consistían en frases sueltas, versos, dibujos y combinaciones de ambos. Desde el punto de vista del contenido, abarcan los más diversos tópicos: las cualidades eróticas de los soldados y los gladiadores, comentarios halagando o denostando a los candidatos a las elecciones, inscripciones sacrales (...), propaganda de los juegos, declaraciones de amor (...), relatos de anécdotas, injurias e insultos, comentarios ingeniosos u obscenos (...), propaganda de prostitutas con sus tarifas y habilidades particulares, versos, reminiscencias de autores griegos y latinos, representaciones fálicas, etc. (Gándara, 2003: 19, las cursivas son propias).

Se puede afirmar que el graffiti es un fenómeno comunicacional al que recurren de manera masiva los jóvenes, quienes así se convierten en los actores principales de un ritual en el que utilizan canales no convencionales, con el fin de divulgar sus mensajes hacia un público que deja de ser receptor, para pasar a ser un testigo obligado de los mismos o un "espectador vicario" (Djukich de Nery y Finol, 1998a:6) de ese juego planteado en las paredes citadinas. Pero sobre todo en espacios cerrados como las salas sanitarias, ese espectador vicario se erige al azar en ese testigo obligado, ya que no puede evitar hacer el papel de público-lector de los escritos con los que allí se encuentra -aunque no estén dirigidos a él-, durante el tiempo que haga uso de ese lugar. Si se asume como destinatario de los mismos, entonces lo manifestará a través de una respuesta o contragraffiti que escribirá al destinador, de manera que surge un diálogo mediato siempre azaroso, toda vez que predomina el anonimato.

En el caso de las salas sanitarias universitarias, la idea va más allá de trascender como "ser" mediante la imposición de una marca territorial o histórica, para activar una especie de "hacer" amoroso y sexual que lleva implícito una apuesta que no es metálica, en la cual el objeto de valor apostado es el sujeto mismo que 


\section{El sexo como apuesta al azar en los graffiti de los baños universitarios}

escribe el graffiti y que se ofrece como trofeo (objeto del deseo) a quien tenga la fortuna de quitarle la máscara, tras la que se oculta al utilizar esa vía no convencional de comunicación.

Ya se sabe que esos mensajes pueden aparecer en espacios abiertos como paredes o superficies de sitios públicos -edificios, parques, trenes- o en espacios cerrados como las salas sanitarias. En estos últimos, el contenido de los graffiti abarca temas políticos, sexuales, amorosos y obscenos (Reisner y Wechsler, 1974: vii). Hasta ahora existen estudios sobre el tema, pero lo abordan principalmente desde el punto de vista psicológico o jurídico, mientras que el presente trabajo lo hace bajo un enfoque socio-semiótico. En el mismo se analizan los graffiti de las salas sanitarias de la Universidad del Zulia (Maracaibo, Venezuela), en las que se observó una fuerte presencia de la temática lúdica sexual.

\section{EL GRAFFITI: ¿ORIGEN AL AZAR?}

"Graffiti" proviene del término italiano graffitto (para el singular, y graffitti para el plural) y significa "dibujo esgrafiado". Hoy día dicho término alude por igual a los escritos y a las imágenes realizadas en paredes o superficies de sitios públicos o cerrados (Mosquera y Djukich de Nery, 2001). Pero hablar del graffiti como escritos o dibujos hechos sobre alguna superficie significa remontarse a la milenaria cultura humana, para rememorar las pinturas realizadas por los hombres del neolítico en las paredes de sus cuevas, en las cuales los antropólogos han hallado muchas veces la clave para develar los misterios de la existencia del hombre y de su naturaleza lúdica.

No está de más recordar que la cultura y los pueblos pueden definirse de acuerdo con su lenguaje (Foucault, 1966; Hjelmslev, 1971). De las diversas manifestaciones de este, el graffiti forma parte de esa simbología que ayuda a conocer variados ángulos de la vida de una sociedad. De esa manera es posible apreciarlo en las referidas pinturas rupestres, que el hombre utilizó para perpetuar en el tiempo escenas que representaban -entre otras cosas- la caza, las ceremonias espirituales, los juegos. 
Alexander Mosquera y DobrilaDjukich de Nery

Telos Vol. 20, No. 1 (2018). 199-222

Sin embargo, investigadores de diferentes disciplinas científicas ubican el surgimiento del graffiti urbano en el mayo francés de 1968 (Reisner y Wechsler, 1974; Abel y Buckley, 1978; Rees, 1981; Posener, 1982; Otta, 1992; Djukich de Nery y Finol, 1998a; Esqueda Torres, 2000; Gándara, 2003) y le atribuyen la cualidad de ser un medio de expresión contestataria de los jóvenes rebeldes de ese entonces. Al principio, los espacios que ocupaban esos mensajes eran abiertos (estaciones de trenes, buses y muros), pero después involucraron igualmente los espacios cerrados (salas sanitarias de colegios y universidades).

En América, Silva (1987) señala la década de los 70 como el inicio del graffiti en Nueva York, específicamente en el metro. De allí se extendió a los espacios metropolitanos, en los que a veces era dibujado en grandes dimensiones y con "aparente ausencia de sentido". No obstante, era la manifestación de la llamada cultura ghetto, en la medida que envolvía los diseños o grafemas realizados por los miembros de grupos marginales como los puertorriqueños, los afroamericanos y los latinos en general, que de esta forma consiguieron una vía de reconocimiento público y pusieron de relieve un juego micropolítico: marcar el territorio (Mosquera y Djukich de Nery, 2001).

De ahí que se afirme que, tanto en espacios abiertos como cerrados, el graffiti posee un claro contenido de transgresión y vandalismo (Djukich de Nery y Finol, 1998a:6), aunque la tendencia actual apunta hacia su uso como arte, en el sentido de que requiere de ciertas habilidades y práctica, además de tiempo de dedicación y deseo, sin que por ello pierda su carácter lúdico.

En el ámbito venezolano, la revisión de la literatura reveló que hay pocos estudios sistemáticos sobre el tópico en cuestión. Excepción hecha de los mencionados trabajos realizados, entre otros, por Djukich de Nery y Finol (1997, 1998a y 1998b), así como por Mosquera y Djukich de Nery (2001). Estas investigaciones reportan como principales temas los mensajes amorosos, agresivos, 
El sexo como apuesta al azar en los graffiti de los baños universitarios

amistosos, humorísticos y sexuales, que aparecen tanto en espacios abiertos como cerrados.

\section{UN ENFOQUE DE LO LÚDICO EN EL “HACER” ESPACIAL}

Según Martín y otros (1995:15), si además de estudiar el juego en el tiempo, se analiza también en función del espacio, se tendrá un conocimiento más completo acerca del Homo ludens. De allí que el análisis sociosemiótico de los graffiti recolectados en las salas sanitarias universitarias se enfocó tomando en cuenta el estado de la situación discursiva (el "ser"), las modalidades de acción (el "hacer"), los terrenos de intervención (las variaciones discursivas y su espacio) y una aproximación a las categorías de la manifestación (las pasiones). En dicho enfoque se tuvieron presente los trabajos de Bremond (1980), Courtés (1980), Eco (1977), Fabri (1995), Greimas y Courtés (1979), Landowski (1997) y Silva (1987).

La anterior caracterización se focaliza desde la mirada del espectador. Es preciso aclarar que el término "focalización" -tomado de G. Genette (en Greimas y Courtés, 1979)- se emplea aquí en el siguiente sentido:

a. Focalizando al objeto de estudio en sí. Es decir, se trata de un procedimiento que consiste en circunscribir una secuencia narrativa por aproximaciones concéntricas sucesivas, hasta lograr unidades de coordenadas espaciotemporales cada vez más precisas o isotopías (Mosquera y Djukich de Nery, 2001).

En cuanto a ese objeto focalizado, se delimitó el enunciado del estado de la situación discursiva (el texto del "ser"), tomando en cuenta que se trata de graffiti realizados en las salas sanitarias masculinas y femeninas de la universidad, así como sus modalidades de expresión que incluyen -además de letras- dibujos y trazos. Así, se buscaron las regularidades lexicales con el fin de conformar isotopías o núcleos de significados, para construir el discurso lexical. En otras palabras, esta construcción se logra al obtener "la repetición de clasemas a lo largo de la cadena sintagmática, de tal manera que le aseguran al enunciado su homogeneidad" (Greimas y Courtés, 1979:197). 
Alexander Mosquera y DobrilaDjukich de Nery

Telos Vol. 20, No. 1 (2018). 199-222

En ese sentido, se caracterizaron isotopías a través de núcleos de significados que muestran figuras de ejes opuestos de significación social como: identidad/anonimato, masculino/femenino y marcas, estas últimas entendidas desde la perspectiva de la semiótica espacial; es decir, para marcar territorialidad, dejar huellas o como mera representatividad del sexo (Landowski, 1997; Augé, 1996; Greimas y Courtés, 1979). Una vez establecidas dichas isotopías, se desglosaron semióticamente los tipos de lenguajes que utilizan los jóvenes universitarios en espacios cerrados como los baños.

\section{Recolección de información al azar}

Para el cumplimiento de esta fase, es preciso aclarar que el presente es un trabajo cualitativo, por lo que la muestra cuantitativa que se tomó es solo una guía para completar la visión conceptual del signo social. Hecha esta salvedad, se debe decir que la recolección de la información se llevó a cabo a través de fichas de contenido elaboradas en el LISA. Con dichas fichas se perseguía conocer aspectos como: temas de los graffiti, ubicación espacial en las salas sanitarias, materiales utilizados para escribir los graffiti y la distribución de estos últimos según el sexo (presencia en las salas de caballeros o de damas). Vale decir que se trabajó, fundamentalmente, con las diez facultades de la Universidad del Zulia (Maracaibo, Venezuela) como muestra, en vista de que dicha institución es la casa de estudios autónoma, nacional y pública con mayor densidad de población estudiantil en Venezuela, con respecto a las otras existentes en el país.

\section{Una muestra del "hacer" espacial lúdico}

La aplicación de las fichas de contenido permitió recolectar un total de 398 graffiti que corresponden a LUZ (Maracaibo, Venezuela). De esta muestra, se seleccionaron como corpus para el análisis sociosemiótico, los 127 graffiti de juegos sexuales recogidos en las salas sanitarias masculinas y femeninas de dicha institución, 
El sexo como apuesta al azar en los graffiti de los baños universitarios

porque como isotopía fue la que predominó en términos numéricos, con lo cual se constató que se mantiene la tendencia reportada en ese sentido por Mosquera y Djukich de Nery (2001). Además, esa isotopía también está subyacente en otras establecidas en la investigación: el juego de lo obsceno, el juego de lo agresivo y el juego de lo amoroso.

\section{RESULTADOS DE LA INVESTIGACIÓN \\ Cuerpo lúdico}

De los 398 graffiti colectados en LUZ-Maracaibo, 70\% se obtuvo en las salas sanitarias masculinas y $30 \%$ en las femeninas. El contenido de los mismos aborda temas como el juego de: lo sexual (32\%), lo obsceno (20\%), lo agresivo (12\%), lo amoroso (7\%), lo humorístico (7\%), lo amistoso (6\%), lo político (4\%), lo poéticofilosófico (3\%), lo religioso (3\%) y otros (6\%) (Véase Anexo 1). Dichos mensajes lúdicos fueron escritos en lugares como las paredes de las salas sanitarias masculinas (54\%) y femeninas (26\%), en las puertas ( $18 \%$ y $9 \%)$ y en los espejos $(0,3 \%$ y $0,3 \%)$. Por otra parte, su elaboración ameritó el uso de marcadores (36\% y 18\%), lápices ( $34 \%$ y $6 \%$ ), bolígrafos ( $2 \%$ y $1 \%)$, tiza $(1 \%$ y $1 \%)$ y otros materiales $(0,5 \%$ y $0,5 \%)$.

Se eliminó el 6\% de los graffiti referidos a "Otros temas" (pues eran poco numéricos, ilegibles, etc.), por lo cual la muestra se redujo a 374 graffiti; pero de ellos, únicamente se trabajó con los 127 relacionados con la isotopía "juego sexual", por las razones ya explicadas.

\section{ANÁLISIS DE LOS RESULTADOS}

\section{Universitarios lúdico-sexuales o cómo mirar detrás de la máscara}

Los resultados dejan ver que los hombres recurren más que las mujeres a este tipo de representaciones lúdicas urbanas y que hay una marcada tendencia de ellos a utilizar sus escritos para expresar básicamente un juego con mensajes de sexo (30\%), obscenos (20\%) y agresivos (14\%). Ellas, por su parte, juegan más con los mensajes de sexo (35\%), obscenos (20\%) y amorosos (12\%). De allí se desprende que los 


\section{Alexander Mosquera y DobrilaDjukich de Nery}

Telos Vol. 20, No. 1 (2018). 199-222

hombres son principalmente "unos jugadores sexualmente obscenos y agresivos", en tanto que las féminas representan a "unas jugadoras sexualmente obscenas y amorosas".

En ambos grupos, los mensajes lúdico-sexuales se manifiestan mayormente a través de los siguientes clasemas que involucran el envite y el azar: a manera de un juego de oferta y demanda de sexo, planteado en forma de avisos de prensa (65\% y $51 \%$ en cada grupo); luego están los juegos de sexo obsceno ( $20 \%$ y $32 \%$ ) y, por último, los juegos de sexo amistoso (15\% y 17\%). Aquí, el envite se manifiesta mediante la apuesta que aparece implícita en el graffiti, que envuelve al mismo jugador-emisor como objeto y trofeo apostado, siempre y cuando el jugador al azarreceptor tenga la "fortuna" de quitarle la máscara tras la cual se esconde y que encierra otras apuestas: "a que no me reconoces" / "a que no me encuentras". Se trata de la metáfora del enmascaramiento que señala Gándara (2003), que da cuenta de lo que sucede en el graffiti, "ya que una máscara no solo oculta sino que además muestra algo" (Gándara, 2003: 60, cursivas en el original) como cara externa de esa máscara, representada normalmente por una firma, iniciales, un nombre de pila (sin dudas falso), el nombre de algún personaje famoso, un pseudónimo o un alias.

Por otro lado, el azar se expresa en el hecho de que el mensaje está dirigido a un jugador al azar-receptor cualquiera (los usuarios de la sala sanitaria que hacen las veces de espectadores), que a su vez se manifestará también como un jugador-emisor al escribir una respuesta o contragraffiti (contra-apuesta) al jugador-emisor inicial, con quien establecerá un diálogo mediato que siempre será azaroso, porque prevalecerá el anonimato.

En ese juego de la oferta y demanda de sexo se puede ver claramente la relación comunicacional con un carácter lúdico que se plantea en las paredes de las salas sanitarias, en la que se desarrolla un "diálogo" mediato o diferido entre un

emisor-oferente y un receptor-demandante de sexo, quienes apuestan a buscar y conseguir sexo mediante esa vía lúdica. Ambos jugadores son anónimos, aunque 


\section{El sexo como apuesta al azar en los graffiti de los baños universitarios}

muchas veces esconden su identidad -como ya se dijo- tras un apodo (una máscara), o en ocasiones expresan alguna característica que les permita reconocerse -lo cual forma parte de ese discurso lúdico-, si se llegara a concretar el "encuentro" pautado en el anuncio publicitario (y así "cobrar" la apuesta al alcanzar el objeto del deseo: el cuerpo/sexo). El actode la enunciación representa como una tensión entre dos modos de existencia: la real y la virtual, y sus estrategias de persuasión modelan el comportamiento del signo (Cfr. Djukich de Nery y Rincón, 1999: 165)

El azar también se presenta cuando el espectador entra en el dilema de si llama o no al número telefónico, que muchas veces aparece en dichos avisos publicitarios de las salas sanitarias masculinas, porque podrían ocurrir varias situaciones: 1) Si llama y se identifica, significa que es homosexual; 2) No es homosexual, pero llama y mantiene el anonimato (predomina la ambigüedad, la máscara); 3) No es homosexual, pero llama porque se muestra interesado o con curiosidad; o sencillamente, 4) Llama para burlarse y hacer catarsis. Por ello, es válido afirmar que el sentido del mensaje de un graffiti no es totalmente verdadero ni totalmente falso; por lo tanto, el discurso verdadero del graffitero-emisor está caracterizado por mantener siempre el mensaje oculto.

Véase el siguiente ejemplo obtenido en un baño para hombres: "Busco pareja.

\section{6142584".}

Para constatar la dificultad de verificar el sentido verdadero del mensaje, los autores de este trabajo llamaron a ese número telefónico y obtuvieron las siguientes vertientes azarosas:

a) Es el número telefónico y se identifica la persona, pero no sabe nada del graffiti en el baño.

b) Sabe del graffiti y no admite que lo sabe.

c) El mensaje lo pudo haber escrito un amigo o enemigo que conoce su número. 
Alexander Mosquera y DobrilaDjukich de Nery

Telos Vol. 20, No. 1 (2018). 199-222

d) El mensaje en sí es ambiguo: ¿busco a un hombre o a una mujer?, aunque el espacio donde aparece (baño masculino) permite concluir que se busca una pareja del mismo sexo.

De hecho, los resultados revelaron que en las salas sanitarias masculinas se tiende más a dirigir el juego de los mensajes sexuales hacia los jugadores del mismo sexo, cosa que no se presenta en las salas sanitarias femeninas, donde lo lúdico involucra preferentemente al jugador del sexo opuesto.

Igualmente, se observa que los jóvenes universitarios se sienten más libres para escribir en esos espacios cerrados, ya que allí consiguen una especie de escudo (o máscara) tras el cual se ocultan, para jugar a no ser descubiertos "in fraganti" mientras le dan rienda suelta a su "hacer" lúdico. Es decir, no se sienten presionados porque "saben" que no serán sorprendidos, ni atrapados ni sancionados por su acción transgresora (Mosquera y Djukich de Nery, 2001), por su juego sexual, obsceno, ilícito y clandestino.

De ahí que también aprovechen la intimidad que les ofrecen las salas sanitarias, para dejar que fluya su accionar lúdico-creador al libre albedrío, sin fijarse en la hora a la que entran a esos lugares ni el tiempo que permanecen allí para terminar su "acto creador" y manifestar su apuesta, pues saben que no serán sorprendidos. Por ello, escogen con calma el espacio lúdico en el cual plasmarán su envite mediante la escritura, muchas veces acompañada de íconos (sobre todo en los baños de hombres). En ese sentido, el espacio lúdico más empleado fue el de las paredes en ambos casos (baños masculinos $71 \%$ y baños femeninos $29 \%$ ). A estas les siguieron las puertas (62\% y $38 \%$ ) y el espejo en muy escaso porcentaje. Aquí se aprecia que la relevancia de la pared como canal de comunicación está determinada por la dimensión que ella ofrece para el hacer lúdico y creativo, toda vez que su amplitud da paso a un espacio más cómodo (Mosquera y Djukich de Nery, 2001) para que el graffitero pueda jugar sin tropiezos. 
Por cierto que en ese "hacer" el jugador-emisor se vale primordialmente de marcadores (61\% en las salas sanitarias masculinas y $39 \%$ en las femeninas) y del lápiz en segunda instancia ( $79 \%$ y $21 \%$ ). Hay un predominio del marcador, ya que este se asemeja al spray empleado por el graffitero para su juego en los espacios abiertos.

En los referidos espacios cerrados, los mensajes aparecen ubicados de tal forma, que los usuarios -de inmediato- entran en contacto visual con ellos y en contra de su voluntad pasan a ser jugadores-receptores, al "hacer" una lectura "obligada" de los mismos, de modo que no pueden escapar al discurso lúdico planteado en el graffiti sexual, pues son convertidos en testigos obligados que se involucran en el juego y en el envite planteado. El graffiti se traduce entonces en un verdadero discurso lúdico oculto, que nada más será conocido por quienes entren a las citadas salas sanitarias y sean atrapados por ese tan atípico juego de envite y azar.

\section{Maneras de ver y jugar}

1. El "Ser" Jugador Masculino: El jugador-emisor, al graffitear, asegura su presencia como jugador y señala sus "no límites" lúdicos sexuales, a pesar de que dice poco porque no puede escribir mucho, en vista de la fugacidad de su paso por ese espacio del que se apropia en su "hacer". De ahí que sus mensajes/apuestas sean directas, osadas y agresivas.

2. El "Ser" Jugador Femenino: Abel y Buckley (1978) afirman que los graffiti femeninos son escasos y poco imaginativos, pasividad que se explica en función de la existencia de normas sexistas, que cohíben a las mujeres de realizar graffiti de cualquier tipo y especialmente si se trata de temas lúdico-eróticos, pues ellas tienden a respetar más los códigos morales y convenciones sociales. Esta opinión también es respaldada por Kinsey, Lomas y Weltman, así como Sechrest y Flores (citados en Abel y Buckley, 1978).

Si bien son pocas "las graffiteras" y sus textos son menos agresivos, lo cierto es que ellas presentan la misma tendencia lúdico-sexista que los varones, la cual está 


\section{Alexander Mosquera y DobrilaDjukich de Nery}

Telos Vol. 20, No. 1 (2018). 199-222

determinada por la revisión que hacen de los paradigmas de belleza, femineidad y comunicación al llegar a la pubertad. Así, el graffitear no solo envuelve un hacer lúdico, sino que se convierte en un franquear (una vez más) la frontera de lo permisible, para entrar en una actividad primordialmente masculina. Entonces, en vez de diferenciarse del varón, las jóvenes lo imitan en su juego, es decir, en su "hacer". De esa manera expresan su otro "yo", que muchas veces se manifiesta a través de las máscaras que utilizan (apodos, nombres ficticios, iniciales, etc.) en ese ritual que despliegan en las paredes y que se concreta en ese juego amoroso-sexual representado por los graffiti (Mosquera y Djukich de Nery, 2001).

En ambos casos, tanto ellos como ellas muestran -con esta forma reiterativa de expresión lúdica- varios aspectos de sus creencias: buscan apoyo y popularidad en su círculo; lo hacen para llamar la atención; es una vía de escape, de desahogo y para liberar deseos (catarsis). Pero, sobre todo, esa manera de expresarse conforma un ritual psicosocial de personalización sexual y por ello recurren a esa expresión lúdica en las salas sanitarias de la universidad.

\section{El jugador/testigo obligado}

En esos espacios cerrados se observó que el modelo semiótico de comunicación sigue la tendencia del que definieron Djukich de Nery y Finol (1997) y Mosquera y Djukich de Nery (2001), en el cual se aprecia a un destinador (graffitero) enviando un mensaje (graffiti) a un destinatario (persona o colectivo) y que incorpora a un receptor-espectador testigo (vicario), para darle veracidad al contenido del mensaje ante el destinatario. No obstante, el vicario -al entrar a la sala sanitaria- se convierte en un jugador testigo obligado de ese mensaje (la apuesta sexual), ya que establece un contacto visual inmediato con el graffiti y es "atrapado" por este, con todo y que él no sea el verdadero destinatario de ese mensaje lúdico-sexual.

Ese jugador testigo obligado muchas veces se asume como destinatario de una apuesta dirigida a un colectivo anónimo -a veces a un individuo en particular-. Es entonces cuando inicia un diálogo mediato con el jugador-emisor del graffiti, en 
El sexo como apuesta al azar en los graffiti de los baños universitarios

ocasiones para rechazar su contenido o para continuar con el juego a través de una conversación mural, cuyo tema central casi siempre es el sexo (Mosquera y Djukich de Nery, 2001).

Esto último lleva a construir un modelo semiótico de la comunicación subyacente en las salas sanitarias universitarias, sobre la base de la isotopía predominante en estos espacios cerrados (graffiti lúdico-sexual). Así, se tiene a un jugador-emisor oferente de sexo (graffitero anónimo, con apodo o marca, que hace las veces de apostador y de objeto del deseo apostado), quien envía un mensaje lúdico (graffiti-aviso publicitario, en el cual encierra un mensaje sexual a manera de envite o apuesta) a un jugador al azar-receptor demandante de sexo (persona o colectivo, también anónimo, con apodo o marca, que se convierte en un apostador al azar), cuya relación es presenciada por un jugador-receptor testigo obligado (espectador usuario de la sala sanitaria), quien en ocasiones se apropia del papel de jugador al azarreceptor. Un esquema lo representa de la siguiente manera:

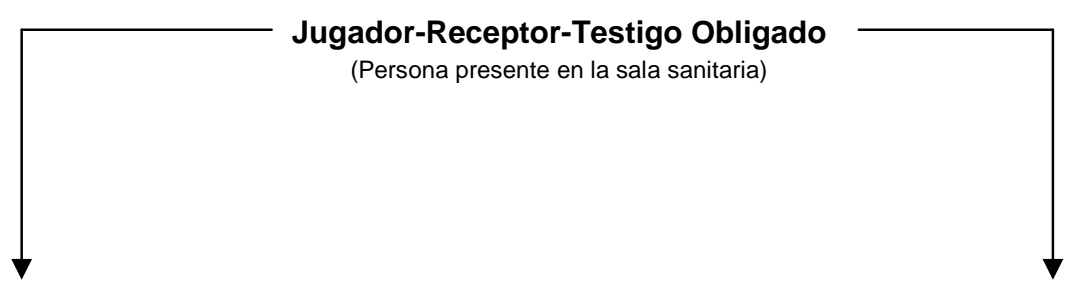

Jugador-Emisor --------> Mensaje lúdico-sexual: Jugador al Azar-Receptor (Oferente de sexo/“Objeto” apostado)La apuesta (Demandante de sexo)

(Aviso Publicitario)

Figura 1. Modelo semiótico de comunicación lúdica-sexual en las salas sanitarias Fuente: Elaboración propia.

Allí se aprecia que el jugador-emisor oferente de sexo y el jugador al azarreceptor demandante de sexo utilizan ese espacio oculto (la sala sanitaria) como máscara, con el fin de expresar un discurso lúdico que casi siempre se dirige a los jugadores del mismo sexo (especialmente en las salas sanitarias masculinas) y por ello restringen su contenido a las paredes de esos recintos cerrados. Este espacio es idóneo 


\section{Alexander Mosquera y DobrilaDjukich de Nery}

Telos Vol. 20, No. 1 (2018). 199-222

para confrontar las tensiones de las existencias virtual y real de los referidos jugadores, quienes entablan otro juego con plena libertad: jugar a "ser yo y parecer otro" o "ser otro y parecer yo", con lo cual también apuestan a no ser descubiertos. Además, allí subyace una conciencia del "no deber graffitear" en espacios abiertos y mucho menos sobre un tema aún considerado tabú (juego sexual) o estigmatizante (jugar a la homosexualidad).

Por otro lado, se observa que el jugador-emisor (oferente de sexo) graffitea con una intención lúdica e íntima, para comprobar el efecto producido por un mensaje que transgredelas normas y violenta la tranquilidad de los usuarios de las salas sanitarias (Mosquera y Djukich de Nery, 2001), quienes al entrar allí se consiguen de inmediato con esa apuesta en las paredes. Por eso se oculta tras una máscara (anonimato, apodo o marca), con el fin de "poder" llevar a cabo su accionar, su atípico juego de envite y azar, así como "mostrar la cara oculta de las cosas, lo que no se decía o se comentaba en voz baja" (Krispin, 2002).

Entre los elementos que forman parte del referido modelo semiótico de comunicación lúdica-sexual se observan los siguientes aspectos:

\section{El jugador-emisor:}

a. Es jugador porque apuesta al sexo: lo solicita a través de los dibujos o las palabras del graffiti. Por ejemplo:

- "Necesito urgente un...que sea cabezón, que mida 16 cm" (LUZ-

Maracaibo).

- "Necesito un macho para el viernes a la 10 am" (LUZMaracaibo).

- "Busco pareja. 0166142584" (ULA-Mérida).

b. Es jugador porque el valor en metálico que se ofrece es sustituido por su correspondiente valor corporal, que es el sexo o alguna zona del cuerpo.

- "Estoy deseoso de darte una buena... llevarte al cielo" (LUZ-

Maracaibo). 
- "Lo tengo grande, peludo y cabezón" (LUZ-Maracaibo).

- "Quiero que me... la pepa" (LUZ-Maracaibo).

2. El mensaje-apuesta: El envite: Corresponde al aviso publicitario de tipo lúdico sexual, que el jugador-emisor escribe en las paredes utilizando marcas sintácticas e icónicas para llamar la atención del receptor-jugador al azar, tales como: los signos de admiración, palabras en letras de molde, sombreadas o en mayúsculas, cambios de color entre el texto y el dibujo, entre otras. En cuanto a los dibujos, en su mayoría son representaciones fálicas y vaginales directas, dibujos en secuencia sobre diversas formas del acto sexual, por citar algunos ejemplos.

- “NO TE ENREDES! Anuncia aquí, en las páginas paredes amarillas, la forma más eficaz de conseguir lo que quieras" (LUZ-Maracaibo).

- "Busco GAYS (LUZ-Maracaibo).

3. El jugador al azar-receptor: El receptor se presenta en dos roles:

a) Sabe que va a conseguir graffiti, es decir, mensajes sobre juegos sexuales. Sin embargo, es un jugador al azar por el hecho de que entra a la sala sanitaria sin saber con qué tipo de juego se va a conseguir. Entre las posibilidades de juegos -del repertorio que se ha obtenido- pueden presentarse las siguientes: dirigidos a él como hombre, como mujer, como homosexual, como travesti o dirigido a cualquier otro jugador, sin especificar su género.

- "Busco GAYS para partirles el...” (LUZ-Maracaibo).

- "Yo era alguien muy sano y bello, fuerte...

Ahora que - SIDA yo mismo me repudio" (LUZ-

Maracaibo).

b) Cuando toma el rol de jugador-emisor: En este caso él también apuesta y le sigue el juego al emisor del primer graffiti.

- "Necesito un macho para el viernes en la mañana

Escribe el día... 26-01-00

Estube y no vinistes 
Alexander Mosquera y DobrilaDjukich de Nery

Telos Vol. 20, No. 1 (2018). 199-222

Yo bine a la hora acordada, siempre he sido puntual, deja tu mensaje, detrás de la puerta hay un mensaje escrito a bolígrafo, ese es mi escrito

Esperare respuesta... 30-10-00" (LUZ-Maracaibo).

\section{CONCLUSIÓN SIN AZAR}

\section{La apuesta sexual en un espacio oculto}

Entre las conclusiones "sin azar" se tiene que los jóvenes venezolanos reiteran su búsqueda de formas alternas o no convencionales de expresión, empleadas principalmente en función lúdica, intimista y transgresora (Djukich de Nery y Finol, 1998a), en este caso a través del graffiti que lleva implícita una apuesta sexual siempre azarosa. Se puede apreciar que esta función cobra más vida y se fortalece en los espacios cerrados como las salas sanitarias de las universidades venezolanas, tal como se evidencia por el tipo de mensaje recurrente que allí prevalece: el graffiti de contenido lúdico-sexual marcado por el envite y el azar.

De ahí que sea válido afirmar que el discurso predominante tiende a ser más bien monosémico (la apuesta sexual), aunque no por ello el "hacer" de este graffitero (apostador o contra-apostador) deja de considerarse un acto de transgresión y vandalismo (Djukich de Nery y Finol, 1998a:6), que se desarrolla bajo el anonimato del jugador (quien a veces usa un apodo o marca como "máscara") y en el que la pared impone su estatus de "telaraña que atrapa a la mosca" (Djukich de Nery y Finol, 1998a), a través de una atípica apuesta signada por la suerte y que el usuario de las salas sanitarias "no puede dejar de ver", toda vez que esta clase de mensaje atrae su mirada, sobre todo si es de contenido sexual.

El graffitero se oculta en ese espacio cerrado para llevar a cabo su accionar, pues lo utiliza como una máscara que le permite no solo expresar su discurso transgresor y vandálico, sino también hablar con libertad de un tema tabú (el juego sexual en el cual él se ofrece como objeto del deseo apostado) o estigmatizante (jugar a ser y parecer homosexual). De hecho, en los baños de los hombres se observó que el 


\section{El sexo como apuesta al azar en los graffiti de los baños universitarios}

jugador-emisor dirige su apuesta sexual casi con exclusividad a los jugadores al azar del mismo sexo, que son usuarios de esos espacios y que representan un público restringido involucrado en ese juego (bien sea como jugador-receptor o solamente como jugador-testigo obligado).

A decir verdad, en las salas sanitarias los referidos usuarios realizan una lectura obligada de los graffiti, ya que entran a un espacio muy pequeño en el cual "no pueden no ver" lo que está a su alrededor. Aquí se manifiesta el azar en el hecho de que, al entrar allí, tales usuarios no saben con qué mensajes se van a conseguir (aunque en principio puedan sospechar que encontrarán los graffiti), si estarán dirigidos a ellos, la manera en que estarán dirigidos a ellos y si los responderán o no.

Por otra parte, en esos espacios cerrados, el graffitero se permite llevar a cabo su acción lúdica creadora a cualquier hora y de manera espontánea, escudado en la tranquilidad que le ofrecen esos lugares íntimos, donde dispone del tiempo necesario con el fin de jugar sin presión y sin el temor de ser atrapado en su "hacer" (Mosquera y Djukich de Nery, 2001), que es otro aspecto al cual apuesta: no ser descubierto. En este "hacer", recurre con mayor frecuencia al uso de marcadores en las salas sanitarias, para dar a conocer su apuesta sexual.

También se observó que los hombres son más dados a entablar este tipo de juego sexual a través del muro, sin dejar de mencionar que las mujeres ya han roto las fronteras de un "hacer" considerado por tradición como masculino y a través del cual expresan un discurso lúdico-sexual, que conjuga una apuesta no metálica y el factor suerte. De esta manera, ya no tratan de diferenciarse del varón, sino que cada vez intentan imitarlo más, tanto en su actividad como en el lenguaje utilizado en su juego sexual. Quizás esto pueda explicarlo el hecho de que la televisión y ahora la globalización han ido sacudiendo códigos de conductas ancestrales, que regían lo masculino y lo femenino (Monsiváis, 1998); es decir, que el graffiti revela además cómo en las grandes ciudades se han ido disolviendo los arquetipos y estereotipos prevalecientes en ese sentido. 
Alexander Mosquera y DobrilaDjukich de Nery

Telos Vol. 20, No. 1 (2018). 199-222

Otro aspecto interesante que se apreció tiene que ver con los graffiti ilegibles que se agruparon en la categoría de "Otros temas" (6\%) y que como tales se eliminaron de la presente investigación. Si bien su análisis ameritaría un estudio más profundo, se puede afirmar que en esa característica de ilegibilidad voluntaria subyace no solo un discurso oculto expresado en un espacio cerrado, al cual nada más tiene acceso la comunidad universitaria; sino que igualmente está implícito "el rechazo por lo establecido, las instituciones y la violencia por la violencia" (Krispin, 2002). Recuérdese el carácter transgresor del graffiti mencionado por Djukich de Nery y Finol (1998a).

En este caso, es válido afirmar que el graffitero a su vez se oculta de manera consciente tras esa máscara, para decirle al mundo que ya no hay palabra posible ni entendimiento; que con el transcurso del tiempo es mayor la brecha del diálogo y que si no se hace algo con urgencia para regresar a la palabra reconocida por todos, nada más "seremos islas de excluidos que tendrán por vecindad tan solo un extraño silencio plagado de garabatos" (Krispin, 2002). A final de cuentas, y para decirlo con Gándara (2003):

(...) operando en sentido opuesto a la censura, el graffiti habilita la denuncia y la exposición a la mirada pública. Permite ejercer la expresión cuando los demás canales están cerrados. Y decimos esto no solo en lo que se refiere a la expresión política o gremial -ya que cuando el poder silencia otros medios de expresión, las paredes de la ciudad dan refugio a las voces silenciadas- sino también en un sentido más amplio, porque como bien intuyó Regina Blume, se trata de un espacio de transgresión del tabú, en el que emergen deseos, ideas, imágenes, temores, que difícilmente encuentran posibilidad de expresión en otros espacios comunicativos. El graffiti delata discursos subterráneos de la sociedad (Gándara, 2003: 119).

Discursos subterráneos que además representan una marca de apropiación territorial, con la cual el graffitero expresa que simbólicamente se ha adueñado de ese espacio íntimo para su juego sexual y lo convierte en un territorio personal al plasmar 
allí su mensaje (apuesta), dándole así voces a las paredes, puertas, espejos, etc., de las salas sanitarias que utiliza en su "hacer" para "ser" y "hacer parecer", a través de una práctica comunicacional espontánea, creadora, social, ingeniosa y que rompe tabúes.

\section{REFERENCIAS BIBLIOGRÁFICAS}

Augé, Marc (1996). Los No Lugares.Gedisa. España.

Abel, Ernest y Buckley, Barbara (1978). The Handwritings on the Wall.Toward a Sociology and Psychology of Graffiti.SeriesContributions in Sociology 27.Greenwood Press. United States.

Bremond, Claude (1980). Comment concevoir un index des motifs. En Le Bulletin

16. École des Hautes Etudes en Sciences Sociales/Centre National de la Recherche Scientifique.France (Pp. 15-29).

Courtés, Joseph (1980). Le motif, unité narrative et/ou culturelle? En Le Bulletin 16. École des Hautes Etudes en Sciences Sociales/Centre National de la Recherche Scientifique. France (Pp. 44-54).

Djukich de Nery, Dobrila y Finol, José Enrique (1997). El graffiti como discurso amoroso. II Congreso Venezolano de Semiótica. Universidad del Zulia. Venezuela.

Djukich de Nery, Dobrila y Finol, José Enrique (1998a). El Graffiti Urbano o el Placer de la Trans(a)gresión. Heterogénesis. Anno VII-No 25 . Universidad de Lunds. Suecia (Pp. 5-13).

Djukich de Nery, Dobrila y Finol, José Enrique (1998b). El Discurso del Graffitero Venezolano y los Temas de su Catarsis. VIII Jornadas Científicas Nacionales de la Facultad de Ciencias. Universidad del Zulia. Venezuela.

Djukich de Nery, Dobrila y Rincón, Sheila (1999). La galantería del próximo siglo: El piropo virtual. IV Congreso Internacional de la Federación Latinoamericana de Semiótica / Asociación Española de Semiótica. Universidad de La Coruña. España.

Eco, Umberto (1977). La Estructura Ausente. Lumen. España.

Esqueda Torres, Luis (2000). Entrevista Personal. Centro de Investigaciones Psicológicas de la Universidad de los Andes. Mérida, Venezuela.

Fabri, Paolo (1995). Tácticas de los Signos. Gedisa. España.

Foucault, Michel (1966). Les Mots et les Choses. Gallimard. France.

Gándara, Lelia (2003). Graffiti. Editorial Universitaria de Buenos Aires. Argentina. 
Telos Vol. 20, No. 1 (2018). 199-222

Greimas, Algirdas y Courtés, Joseph (1979). Semiotique. Dictionnaire Raisonne de

la Theorie du Langage. Hachette Universite. France.

Hjelmslev, Louis (1971). Prolégoménes a une Théorie du Langage. Minuit. France.

Krispin, Karl (2002). Los extraños garabatos. Diario El Nacional. Martes 12 de febrero (A/7). Caracas. Venezuela.

Landowski, Eric (1997). Presences de l'Autre. Essais de Socio-semiotique. v. II. PUF. France.

Martín, Ana; Ramírez, Cristina y Martínez, Amparo (1995). Actividades Lúdicas.

Editorial Popular. España.

Monsiváis, Carlos (1998). Las migraciones culturales: del rancho al Internet. En

Venezuela: Tradición en la modernidad. 3er Simposio sobre Cultura Popular.

Universidad Simón Bolívar. Fundación Biggot y Equinoccio. Venezuela.

Mosquera, Alexander y Djukich de Nery, Dobrila (2001). El espacio oculto del discurso del graffiti en las salas sanitarias universitarias. OPCIÓN.Año 17, $\mathbf{N}^{\circ}$ 36.Venezuela (Pp. 48-67).

Otta, Emma (1992). Graffiti in the 1990s: A study of inscription on Restroom Walls. Journal of Social Psychology.133 (4). Routledge. United Kingdom (Pp. 589-590). Posener, Jill (1982). Spray it Loud. Routledge \& Kegan.United Kingdom.

Rees, Nigel (1981). The Graffiti File.George Allen \& Unwin. United Kingdom.

Reisner, Robert \& Wechsler, Lorraine (1974). Encyclopedia of Graffiti.MacMillan. UnitedStates.

Silva, Armando (1987). Punto de Vista Ciudadano. Focalización y Puesta en Escena del Graffiti. Instituto Caro y Cuervo. Colombia. 
El sexo como apuesta al azar en los graffiti de los baños universitarios

ANEXO 1

Figura 2. Graffiti lúdicos por temas y sexo en LUZ (\%)

$\%$

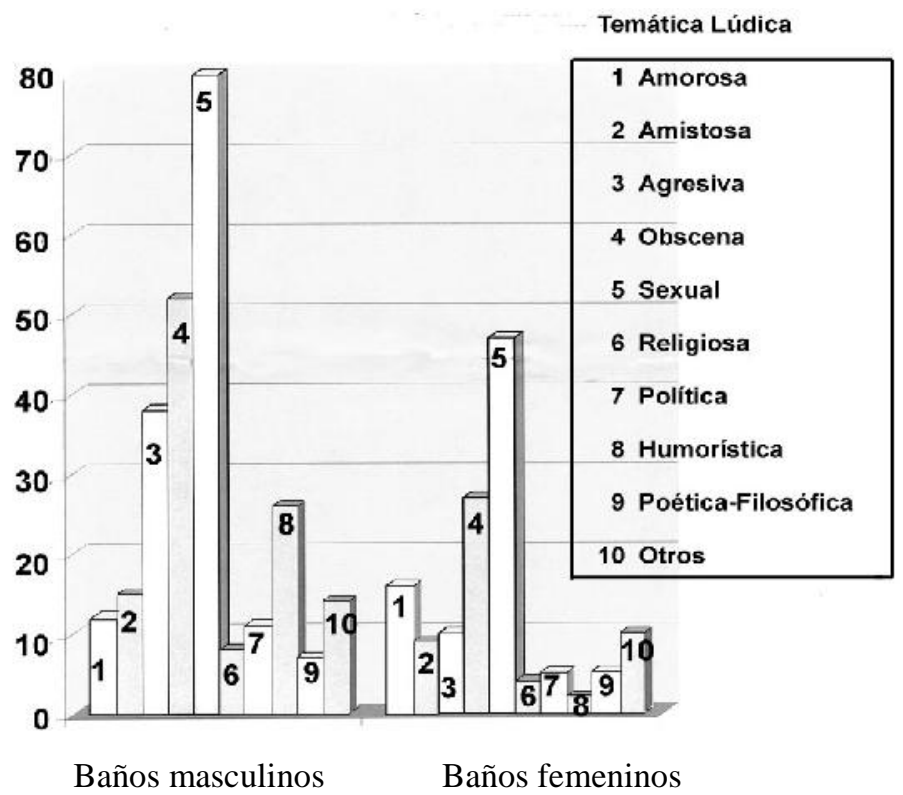

Fuente: Elaboración propia. 